\section{Nasal High Frequency Oscilla- tory Ventilation (nHFOV): Rescue Treatment for Respira- tory Distress Syndrome in Preterm Infants}

Sir,

Noninvasive ventilation strategies have been shown to decrease neonatal mortality in preterm infants with respiratory distresssyndrome (RDS). Nasal high frequency oscillatory ventilation (nHFOV) is a noninvasive technique which offers better carbon dioxide elimination and increased functional residual capacity. The oscillations of nHFOV help to avoid gas trapping and maintain mean airway pressure. ${ }^{1}$ We are reporting our novel experience at the use of nHFOV in a preterm baby with RDS.

We came across a clinical situation when a preterm male weighing $1.7 \mathrm{~kg}$, born at $30 \pm 3$ weeks of gestation developed RDS at birth. First dose of surfactant was given in view of $x$-ray findings of RDS. Humidified high flow oxygen was started at 6 liter per minute with oxygen concentration of $50 \%$. Subsequently, baby developed increased work of breathing, persistent respiratory acidosis and increase in oxygen requirement.

Decision wastaken togive a trial of nasal high-frequencyventilation combined with non-invasive continuous positive airway pressure (CPAP) support with Medin CNO CPAP machine, (Hamilton Medical, Switzerland) at 8 hours of life instead of endotracheal intubation. A frequency of $10 \mathrm{~Hz}$ was established as an initial setting which was subsequently adjusted to the patient needs. CPAP pressure of $5 \mathrm{~cm} \mathrm{H}_{2} \mathrm{O}$ was required with regard to oxygenation and breathing effort. Amplitude was adjusted to 10. Breathing gas flow was adjusted at 7 liters per minute with $\mathrm{FiO}_{2}$ of 0.6 .

A vivid improvement in clinical condition was noticed on nHFOV with a decrease in work of breathing, $\mathrm{PCO}_{2}$ normalised and oxygen requirement decreased to $40 \%$ within four hours. Baby remained well and his parameters were tapered gradually. Baby was switched to nasal CPAP (nCPAP) after 48 hours followed by humidified low flow oxygen therapy. Expressed breast milk feeding was started and progressed gradually to full feed. Baby was discharged home on 7th day of life in room air and oro-gastric tube feeding.

It has been postulated that nHFOV is a technique which might reduce $\mathrm{pCO}_{2}$ by enhancing $\mathrm{CO}_{2}$ diffusion in the pharynx and larynx areas, thus decreasing the need for invasive ventilation. ${ }^{2}$ The combined effect of CPAP results in an increase in $\mathrm{paO}_{2}$, indicating an increased functional residual capacity and/or alveolar recruitment. Thus, the benefits of CPAP are augmented by the pronounced ventilator effect of high frequency oscillations. ${ }^{3}$ In addition, no synchronization is required. ${ }^{4}$

To our knowledge, this is the first experience of nHFOV in Pakistan. It suggests that treatment with nHFOV may be a beneficial rescue strategy in preterm infants with RDS to minimise the need for invasive mechanical ventilation.

\section{CONFLICT OF INTEREST:}

Authors declared no conflict of Interest.

\section{AUTHORS' CONTRIBUTION:}

SRA, VK: Conception and design work.

$B Q, H K$ : Data collection.

$\mathrm{AK}, \mathrm{BQ}, \mathrm{HK}$ : Data analysis and interpretation.

VK, AK: Drafting the letter.

SRA: Critical revision of final version for publication.

\section{REFERENCES}

1. Chen L, Wang L, Ma J, Feng Z, Li J, Shi Y. Nasal highfrequency oscillatory ventilation in preterm infants with respiratory distress syndrome and ards after extubation: $A$ randomized controlled trial. Chest 2019; 155(4):740-8.

2. Chan J, Jones LJ, Osborn DA, Abdel-Latif ME. Non-invasive high-frequency ventilation in newborn infants with respiratory distress. Cochrane Database Syst Rev 2017; 2017(7):CD012712.

3. Mathai SS, Raju U, Kanitkar M. Management of Respiratory Distress in the Newborn. Med J Armed Forces India 2007; 63(3):269-72.

4. Sweet DG, Carnielli V, Greisen G, Hallman M, Ozek E, Te Pas $A$, et al. European consensus guidelines on the management of respiratory distress syndrome. Neonatology 2019; 115(4):432-50.

Vikram Kessani, Azeem Khan, Bibi Quratulain, Haleema Khalid and Syed Rehan Ali

The Indus Hospital, Karachi, Pakistan

Correspondence to: Dr. Syed Rehan Ali, The Indus Hospital, Karachi, Pakistan

E-mail: rehan.ali@tih.org.pk

Received: May 23, 2019; Revised: September 16, 2019;

Accepted: September 22, 2019

DOI: https://doi.org/10.29271/jcpsp.2020.07.771 